\title{
Ludwig van Beethoven'ın Op.57 No.23 Appassionata Sonatı'nın Form ve Yorumculuk Bakımından İncelenmesi
}

\author{
Form and Interpretation Analysis of Ludwig van Beethoven's Op.57 No.23 \\ Appassionata Sonata
}

\author{
Ecem ALNIAÇIK iD 1
}

\begin{abstract}
Öz
18.-19. yüzyılda yaşamış Alman besteci Ludwig van Beethoven, piyano, oda müziği ve orkestra için yazdığı eserlerle, müzik tarihinin ve piyano edebiyatının önemli bestecilerinden biri olmuştur. Klasik dönem ile romantik dönem arasında bir köprü oluşturmuş, Joseph Haydn ve Wolfgang Amadeus Mozart gibi dönemin önde gelen bestecilerinden etkilenip, onların stillerini geliştirerek kendi üslubunu ortaya çıkarmıştır. Bestecinin üç ayrı dönemde incelenen yaratıcılığının orta (ikinci) dönemine denk gelen, Op. 53 'Waldstein Sonatı'yla aynı zamanlarda bestelediği Op. 57 'Appassionata Sonatı', bestecinin üslubunun değiştiği, kendine özgü bir stil ortaya koyduğu başlıca piyano sonatlarındandır. Üç bölümden oluşan bu sonatın birinci ve üçüncü bölümleri 'sonat allegro', ikinci bölüm ise 'çeşitleme' formunda bestelenmiştir. $\mathrm{Bu}$ sonatta, bestecinin sonat formuna getirdiği yenilikler net bir şekilde görülmektedir. Bu dönemde değişen form ile birlikte lirik anlatım tarzı da dönemin önemli özelliklerindendir. $\mathrm{Bu}$ da eserlerini yorumlamada yeni fikirlerin ortaya çıkmasına sebep olmaktadır. Bu çalışmada, 'Appassionata Sonatı', bestecinin değişen üslubu ve diğer sonatlarına göre farklılıklarıyla birlikte incelenecek, form analizi yapılacak ve Wilhelm Kempff, Alfred Brendel ve Vladimir Horowitz gibi yetkin piyanistler tarafından farklı yorumlarına yer verilecektir. Bu çalışmanın amacı, Ludwig van Beethoven'ın orta dönem sonatlarına örnek olarak, ‘Appassionata Sonatı'nı yorumlamak isteyen piyanistlere, eserin form analizi ve farklı yorumlarının karşılaştırılmasını sunarak katkı sağlamaktır.
\end{abstract}

Anahtar Kelimeler: Beethoven, piyano, sonat, op.57 Appassionata Sonat1

Makale Türü: Araştırma

\begin{abstract}
German composer Beethoven who lived in the 18th and 19th centuries became one of the milestones in the history of music and the piano repertoire with his compositions. Beethoven played a transitional role between the classic period and romantic period. His compositional style was derived from the influence of Joseph Haydn and Wolfgang Amadeus Mozart. He adopted their traits into his own style as well as enhancing them. Beethoven's compositional life is often divided into three periods. In his Waldstein Sonata Op.53 and Appasionata Sonata Op.57 that were composed in his middle period, his style began changing towards a more unique and personal path. The first and third movements of this sonata are in a sonata allegro form whereas the second movement is in a variation form. This sonata displays very clearly the innovations that Beethoven brought to the Sonata Form, one of which is the style of lyrical expression. This led to the emergence of new ideas regarding interpretations of his works. This study will focus on the aspects of the Appasionata Sonata such as Beethoven's volatile compositional style and the differences between this sonata and its contemporaries along with a structural analysis. The readers will also find a comparison section in which the interpretations by Wilhelm Kempff, Alfred Brendel and Vladimir Horowitz is discussed. This study is aimed to give guidance to pianists who

interpret the Appasionata Sonata by presenting a structural analysis and comparison between various interpretations in the lights of examples from his middle period.
\end{abstract}

${ }^{1}$ Uludağ Üniversitesi, Sosyal Bilimler Enstitüsü, ecem.alniacik@ hotmail.com.

Atıf için (to cite): Alnıaçık, E. (2020). Ludwig van Beethoven'ın Op.57 No.23 Appassionata Sonatı'nın form ve yorumculuk bakimindan incelenmesi. Afyon Kocatepe Üniversitesi Sosyal Bilimler Dergisi, 22(4), 1173-1186. 
Keywords: Beethoven, piano sonata, op.57 Appassionata Sonata

Paper Type: Research

\section{Giriş}

Viyana klasikleri arasında yer alan Ludwig van Beethoven, 1770 yilında Almanya'nın Bonn şehrinde doğmuş, 1827 yılında Viyana'da hayata veda etmiştir. Klasik dönemden romantik döneme geçiş sürecine büyük katkı sağlamış ve döneme damgasını vurmuş bestecilerden biri olarak kabul edilmiştir. Dokuz senfonisi, beş piyano konçertosu, otuz iki piyano sonatı, on altı yaylı dörtlüsü ve hayatı boyunca yazdığı tek opera olan 'Fidelio' en çok bilinen eserlerindendir.

Fransız Devrimi ve devrimin getirdiği yenilikler Beethoven'ın gençlik yıllarına denk gelmektedir. Değişen toplum değerleri, sanatçının toplum içinde yeni bir kimlik kazanması, eserleriyle toplumun sesini duyurması dönemin diğer sanatçıları gibi Beethoven'ın da müziğine büyük ölçüde yansımıştır. Beethoven eserlerinde kendi iç dünyasını, duygularını yoğun bir biçimde anlatmıştır ki bu da romantik akıma kapılarını açmıştır. (İlyasoğlu, 1994, s. 70-71)

Beethoven, 18. yüzyılı kapsayan, dünya tarihini etkileyen birçok olayın yaşandığı, aynı zamanda insanlığı etkileyen duyguların da geliştiği bir dönem olan büyük değişim döneminin insanı olmuştur. Haydn ve Mozart'tan o zamana kadar geliştirilmiş ve gelişmeye açık olan stil ve biçimleri alarak romantik dönemin en önemli kaynaklarından biri haline gelmiş, iki yüzyıl arasında geçiş bestecisi olarak tarihe geçmiştir. (Boran ve Şenürkmez, 2010, s. 161)

Müziğe babası ile başlayan Beethoven, ilerleyen yıllarda bestecilik eğitimini Christian Gottlob Neefe, org derslerini Gilles van den Eeden, klavye derslerini Friedrich Pfeiffer, keman ve viyola derslerini de Franz Rovantini ile sürdürmüştür. Viyana'ya taşınması ile dönemin önde gelen besteci Joseph Haydn ile çalışmalarına devam etmiştir.

1792 yılında Mozart'ın ölümünün ardından Beethoven, J. Haydn ile tanışıp, çalışmak üzere Viyana'ya gitmiştir. Kısa sürede yeteneğiyle Haydn'ın da dikkatini çeken Beethoven, hem piyanist hem besteci olarak adını duyurmaya başlamıştır. Fakat bir süre sonra Haydn'ın, Beethoven'ın yenilikçi fikirlerini kabul etmemesi sebebiyle derslere son vermiş ve çalışmalarını Salieri ile devam etmiştir.

O yıllarda Viyanalı soylular Beethoven'1 'yeni Mozart' olarak görmüş ve ona büyük maddi destekte bulunmuşlardır. Beethoven ise bu isimlerden yaklaşı yirmisine ithaflarda bulunmuştur. İsmi geçen soylulardan en büyük yardımı ise zamanında Mozart ile de çok yakın ilişkide olan Prens Karl Lichnowsky yapmıştır. (Lockwood, 2013, s. 74) 1794 yılında kendisi de zamanında Mozart'tan ders almış olan ve konağını bir müzik derneği haline getiren prens Lichnowsky, ülkesinin prensliğinden desteği kesilen Beethoven'ı kendi konağına davet ederek onu bu müzik akademisinin başına getirmiştir.

1798 y1lında işitme problemleri başlayan Beethoven'ın hastalığı üç yıl içinde sağırlığa dönüşmüştür. Oldukça zor bir dönem geçirmesine rağmen birçok önemli eserini bu dönemden sonra bestelemiş, bu dönemde bestelediği sonatlardan ilk üçünü Haydn'a ithaf etmiştir. Bu ilk dönem sonatları incelendiğinde görülmektedir ki besteci stil olarak hocası Haydn'a oldukça yakındır. (Boran ve Şenürkmez, 2010, s. 163) Bu dönem, Bach'ın 1717-1723 yılları arası Köthen'de, Haydn'ın 1770'lerin başında Esterhazy'de, Mozart'ın ilk beş yılı içinde yaptığı gibi Beethoven'ın da olgunluğa eriştiği, müziğini değiştirdiği yıllar olmuştur. Bestecinin en ünlü eserlerini bestelediği dönem olması sebebiyle bu dönem Beethoven'ın kariyerinin merkezi kabul edilmektedir. (Lockwood, 2010, s. 209)

Beethoven'1n orta(ikinci) dönemi 3. senfonisi 'Eroica' ile 1803 yılında başlayarak 1815 y1lına kadar devam etmiştir. Bu dönemde Beethoven'ın müziğinde gerilim ve dokusal yoğunluk artışı görülmektedir. (Altay, 2014) Ayrıca sağırlığının da ilerlemesiyle Beethoven'ın depresif 
ruh hali eserlerine yansımıştır. Bu dönemde bestelediği eserlerde kahramanlık ve mücadele fikri yoğun bir şekilde görülmektedir.

1816 yılı ile Beethoven'ın birçok önemli eserini bestelediği 'olgunluk dönemi' başlamıştır. $\mathrm{Bu}$ dönemde bestecinin eserlerinde yapısal olarak yenilikler, yeni kuruluşlar ile birlikte özellikle özgün ifadeleri ve derin duyguları yansıttığı görülmektedir. Bunlara verilecek başlica örnekler; Missa Solemnis Op. 123, 9. senfoni gibi orkestra eserleridir (Uzar, 2017, s. 381). Bestecinin olgunluk dönemi üslubu, en büyük eserlerinden biri olan Op.101 Piyano Sonat1 ile ortaya çıkmıştır. Bu eserle yeni bir estetik arayışa girmiş, hareketler arası kontrastı ön plana çıkarmış, kendi eserlerinde yeni, başka dönemlerde yazılmış eserlerde nadiren görülen yeni bir ses arayışına girmiştir. Yine bu dönem eserlerinde kullandığı melodik ve kontrpuan içeren unsurlar sebebiyle Bach stiliyle kendi stilini sentezlediği görülmektedir. (Lockwood, 2010, s. 356-358) 7. ve 8. senfonilerin ardından Beethoven, büyük bir dini eser bestelemek istemiştir. Koro ve senfoniyi birleştirdiği bu büyük eseri, 9. senfonisinin ilk seslendirilişi 1824 yılında yapılmıştır. Senfoninin büyük başarısının ardından Beethoven hemen bir 'Requiem' bestelemek istese de hastalığı buna izin vermemiş, çalışmalarına devam edememiştir. Beethoven, bu dönemde bestelediği eserlerde biçimsel olarak birçok farklılıklar görülmüştür. Özellikle piyano sonatlarında teknik olanakları geliştirirken, formun da sınırlarını zorlamıştır. Örnek; Op.106 Hammerklavier piyano sonatı (Boran ve Şenürkmez, 2010, s. 167).

$\mathrm{Bu}$ çalışmada, Beethoven'ın 'Appassionata Sonatı'nda kullandığı stil, eserin form analizi ve yorum karşılaştırmaları incelenecek, değiş̧en stilinin eser yorumu üzerindeki etkisi araştırılacaktır.

\section{Appassionata Sonatı Op.57 No.23}

Op. 57, 23 numaral1 'Appassionata Sonat'1 Ludwig van Beethoven'in s1klikla yorumlanan sonatlarından biri olup, 1805 yıllında bestelenmiş ve 1807 yılında yayımlanmıştır. Sonata 'Appassionata' başlığı besteci tarafindan değil, eserin karakterine uygun olarak editörler tarafından verilmiştir. 'Appassionata' kelime anlamı olarak İtalyancada tutkulu ve ihtiraslı bir anlatım anlamına gelmektedir. Bestecinin klavye sonatını yeniden şekillendirmekte olduğu bu dönem 'Appassionata Sonatı' üzerine çalışırken kullandığı deftere yazdığı 1805 tarihli bir notta:

\footnotetext{
"final her zaman daha basit oluyor. Aynı şey bütün piyano müziklerim için de geçerli. Piyano müziğim benim üzerimde neden her zaman, özellikle de kötü çalındığında çok kötü bir izlenim bırakıyor, Tanrı bilir." diye belirtmiş̧ir. (Lockwood 2010: 301)"
}

Sonat, 'Allegro assai', 'Andante con moto', 'Allegro ma non troppo' olmak üzere üç bölümden oluşur. Beethoven'ın Franz von Brunswick'a adadığı bu sonatın bestelendiği döneme bakıldığında, bestecinin hayatının orta dönemine denk geldiği görülmektedir. Bu dönem bestecinin de kendini 'verimli ve yaratıcı' olarak tanımladığı bir dönemdir. Klasik form anlayışında uzaklaşarak kendine özgü bir stil ortaya koymaktadır. Dönemin başlıca temaları eşitlik, özgürlük ve kardeşlik olmak üzere Fransız Devrimi'nin de ideallerini yansıtan bu üç kavramdır. Bu temalar Beethoven'ın müziğinde ise kendini özgürlük, kahramanlık ve mücadele ile ortaya çıkarmıştır. Bununla birlikte Beethoven'ın lirik anlatım tarzı bu dönemin en önemli özelliklerindendir. Bu dönemin en öne çıkan yapıtı kahramanlık anlamına gelen, Napolyon'a ithaf ettiği 'Eroica' başlıkl1 3. senfonisidir. Bu eser, bestecinin kendine özgü bestecilik özelliklerini içeren ilk büyük ölçekli yapıtı olmakla beraber 19. yüzyıl romantizminin senfoni anlayışının ilk örneklerini içermektedir. İlk kez bu eserde bir tema, farklı yerlerde, farklı bölümlerde tekrar tekrar değiştirilerek kullanılmıştır. Yine bestecinin tek operası olan 'Fidelio'da da kahramanlık teması görülmektedir (Boran ve Şenürkmez, 2010, s. 165).

Besteci bu dönemde, 4. ve 5. Piyano Konçertoları, üçlü konçerto, Op.47 keman konçertosu, 5 yaylı dörtlü, Op.53 Waldstein Sonat1, Op. 57 Appassionata Sonat1, No.3-8 Senfoniler, Fidelio Operası gibi önemli eserler bestelemiştir. 
Klasik dönemde bestecilerin sıklıkla tercih ettiği form 'sonat formu' olmuştur. Sonat formu döngüsel bir form olup, senfoni, oda müziği ve sonatlarda kullanılmıştır. Ludwig van Beethoven ise sonat formuna formal ve müzikal olmak üzere birçok yenilik getirmiştir. Bunların başında, formları esnetip genişletmesi, gerilim-çözülüm ilişkisi ve armonik değişiklikler gelmektedir. Eserlerinde müzik yeni bir anlayışa, romantizm akımına doğru yönelmeye başlamıştır. Bach, Händel, Haydn ve Mozart'ın klasik yanlarını özümsemiş, onların fikirleriyle kendi tarzını oluşturma yolunda ilerlemiştir (Karaçil, 2010, s. 14).

\subsection{Birinci Bölüm 'Allegro assai'}

Sonat formunda bestelenmiş eserlerin ilk bölümleri genellikle 'sonat allegro' formundadır. Beethoven'ın op.57, no.23 sonatının birinci bölümü olan 'Allegro assai', sonat allegro formunda bestelenmiştir. Fa minör bölümün 'sergi' bölmesi 1.-65. ölçüler arasıdır. Bu bölümün karamsar, depresif karakterli 1. temas1, 'bileşik aperyodik' ${ }^{2}{ }^{3}$ temadır. Şekil 1'de görülen temel fikir, fa minör tonunda 1.-4. ölçüler arasında duyulduktan sonra 4.-8. ölçüler arasında sol bemol minör tonunda tekrar eder. Böylece sergi bölmesinin sunum cümlesi kadans yapmadan bitmiş olur ve 9. ölçüde, temel fikrin üçüncü ölçüsünden alınan parçalanma başlar.

Şekil 1. Sergi bölmesi, temel fikir. (1.-4. ölçüler)

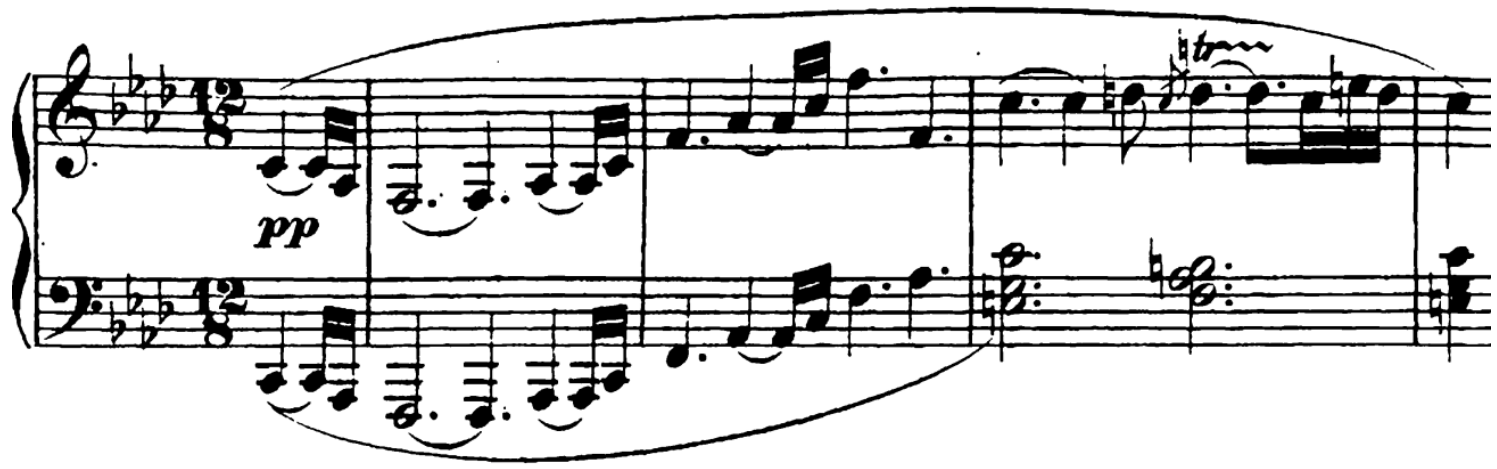

9. ölçüde, Şekil 2'de görüldüğü gibi Beethoven'ın sonraki yıllarda yazacağı 5 . Senfonisi'nin 'kader teması' duyulur. İki ölçülük kadansa hazırlığın ardından 14. ölçüde 'parlak stilde' (brillant style) kadans cümlesi duyulur ve 16. ölçüde kırık kadansla 1. tema bitmiş olur.

Şekil 2. 5. Senfoni’den bir motif (kader teması) (10. ölçü)

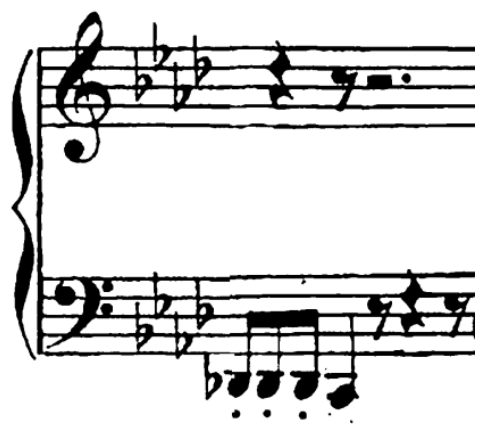

16. ölçüde temel fikrin başı duyulur ve fa minör akorlarla tema devam eder. Burada temel fikir tekrar duyurulmak istenmiştir. 23. ölçüyle birlikte tonaliteden uzaklaşma başlar.

\footnotetext{
2 Periyot, yapısı itibariyle "öncül" 2 ve "soncul" 3 olarak anılan iki cümleyi içerir. Burada esas olan, her iki cümlenin de birer kadansla sonlandırılmasıdır. Yaygın olarak (özellikle klasik dönemde) simetrik bir organizasyon içeren periyotlar, dördü "öncül”, dördü ise "soncul" olmak üzere toplam sekiz ölçüden oluşurlar. Ancak bu durum her zaman geçerli değildir "Aperyodik" yapılar simetrik bir (tipik olarak sekiz ölçülük) tematik kuruluş türüdür. Burada "aperyodik" 8 terimi belirli bir türü işaret etmektedir. Zira aperyodik yapılar da, tıpkı periyotlar gibi belli başlı niteliklere sahip sıkı tema kuruluşlarıdır. (Altay. 2011, s. 5, 11)

${ }_{3}^{3}$ Analizde kullanılan terminoloji, William E. Chaplin'in Classical Form başlıklı kitabında kullandığı terminolojinin Gökçe Altay tarafindan Türkçe'ye uyarlanmış halidir.
} 
24. ölçüde yeni temaya hazırlık amaçlı mi bemol majör tonunda 'geçit' başlar ve 35. ölçüde la bemol majör tonunda 'yan tema' duyulur.

Yan tema, iki gruptan oluşur. 35.-51. ölçüler aras1 1. gruptur. (Şekil 3) 1. grup, temanın çevrim çeşitlemesi olsa da karakter olarak tamamen karşıt, neşeli bir karakterdedir. Burada tema kuruluşu periyottur. 39. ölçüde temel fikir tekrar eder ve ardından kadans başlar. Tam otantik kadansın ardından 51. ölçüde yan temanın la bemol minör tonunda, bileşik aperiyot tema kuruluşunda 2. grubu başlar. (Şekil 4) Bu tema 1. grup gibi kibar değil aksine çok daha agresif karakterdedir. 51.-54. ölçüler arası duyulan tema, 55.-58. ölçüler arası tekrar duyulur. Bir ölçülük uzamanın ardından tam otantik kadansla tema sona erer. 61.-65. ölçüler arası 'kodetta'dır.

Şekil 3. Yan tema, 1. grup (35.-39. ölçüler)

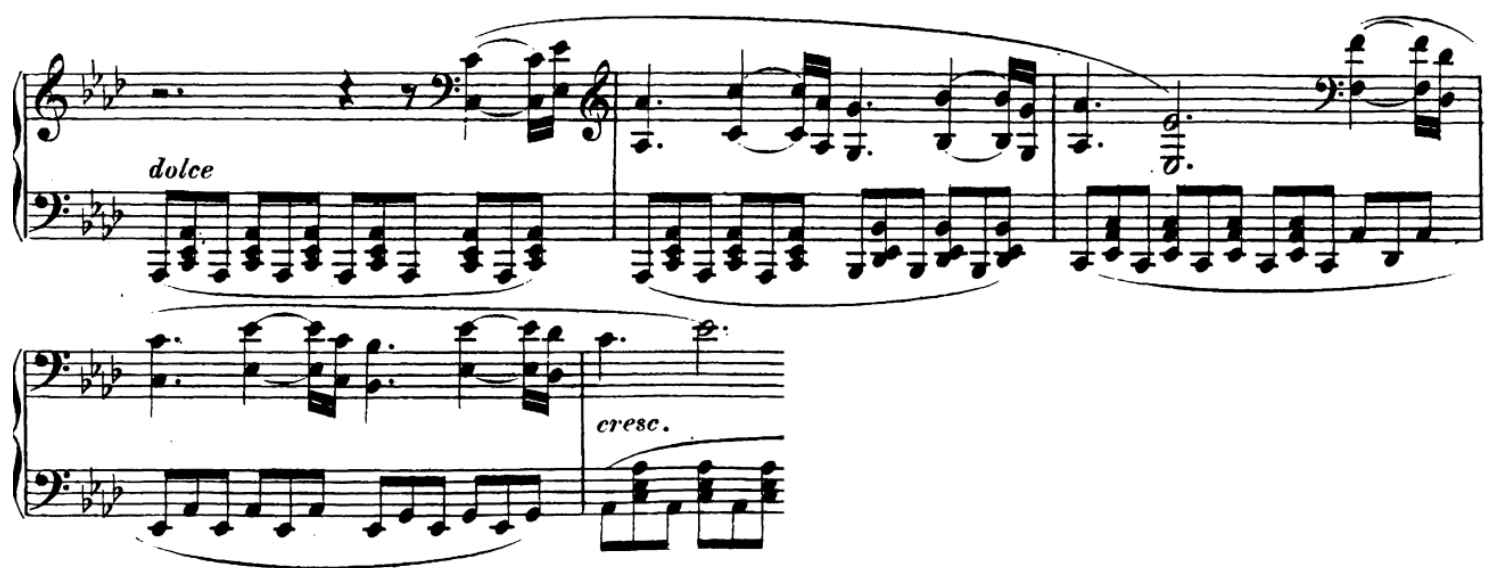

Şekil 4. Yan tema, 2. grup (51.-54. ölçüler)
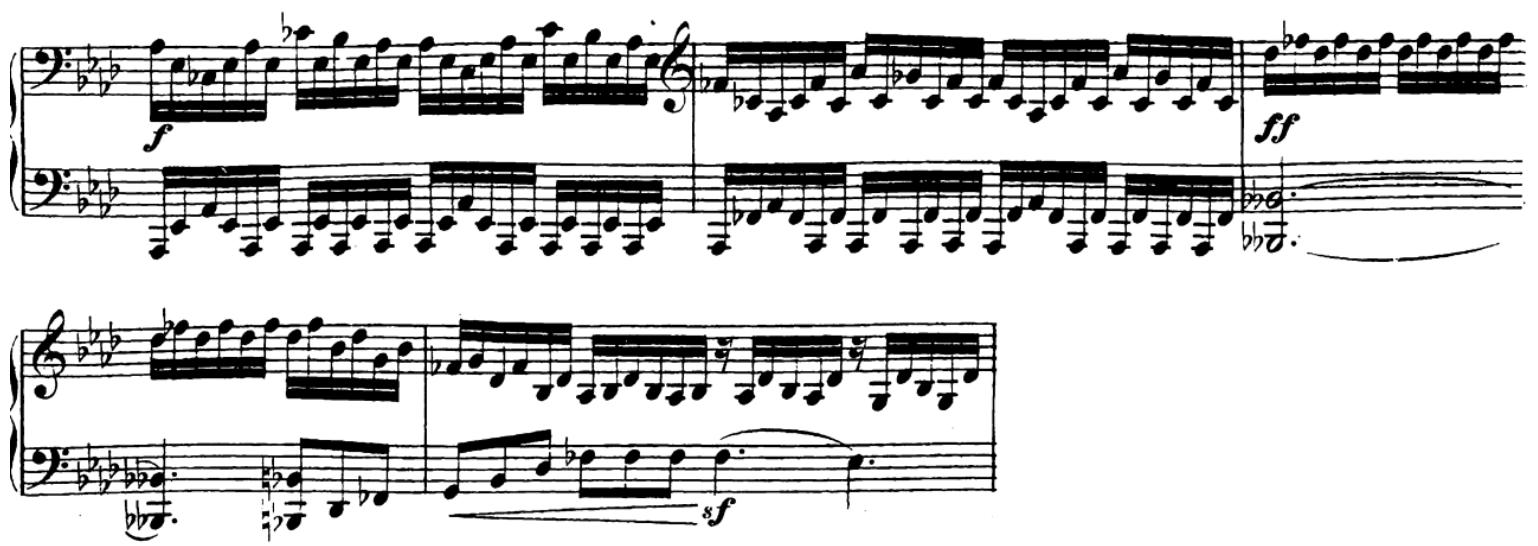

65.-135. ölçüler 'gelişme bölmesi'dir. 65.-78. ölçüler armonik ve tonal kararlılığın bozulduğu 'ön hazırlık'tır. Bu grupta 1. temadan motifler parçalanarak kullanılmıştır. Ön hazırlık, 78. ölçüde mi majör tonunda yarım kadans ile biter ve gelişme bölmesinin 'ana gövde'si başlar, 130. ölçüye kadar devam eder. Burada 'firtına ve gerilim' (Almanca: Sturm und Drang) estetik anlayışı yansıtılmıştır.

Ana gövde, üç grup halinde incelenmiştir. 1. grup, 78. ölçüde başlar, 93. ölçüde sona erer. Burada 1. temanın çıkıcı motifi farklı tonlarda gelmektedir. Ardından 93. ölçüde 2. grup başlar ve 109. ölçüye kadar devam eder. Burada ise sergi bölmesinin geçidindeki motif kullanılmıştır. Tonal karışıklığın ardından 109. ölçüde re bemol majör tonunda 3. grup başlar, modülasyonlarla 123. ölçüye kadar devam eder. Burada ise yan temanın 1. grubu kullanılmıştır.

122. ölçüde ana ton olan fa minörün dominant akorunun duyulmasının ardından 123. ölçüde 'geri geçit' başlar. Geri geçit kırılan arpejlerle başlar ve bölünerek 130. ölçüye kadar 
devam eder. 130. ölçüde ise sergi bölmesinde de kullanılan 'kader teması' tekrar duyulur. İki ölçülük bir hazırlığın ardından 135. ölçüde 'yeniden sergi’ bölmesi başlar.

Yeniden sergi bölmesi ana ton olan fa majör tonunda, sergi bölmesinden farklı olarak ise tema, basta 'do' notası eşliğiyle birlikte duyulur. Sergi bölmesinde olduğu gibi burada da temel fikrin tekrar gelişinin ardından 163. ölçüde do majör tonunda geçit başlar. Yan temanın 1. grubu fa majör, 2. grubu ise fa minör tonundadır. 200. ölçüde tam otantik kadansla sona eren yeniden sergi bölmesi iki ölçü uzadıktan sonra 204. ölçüde 'koda-1' başlar.

Koda-1, 1. temadan alınan motifle başlar. Motifin arka arkaya birkaç kez duyulmasının ardından, 210. ölçüde yan temadan 1. grubun teması duyulur ve bu tema parçalanarak devam eder. Ardından 218. ölçüde geçit nitelikli, arpejlerden oluşan, parlak stilde bir grup sekvensler halinde gelir ve parçalanarak devam eder. 227. ölçüde ise yine parlak stilde, arpejlerden oluşan bir diğer grup başlar ve 235. ölçüde sonlanır. Yine bu ölçüde sergi bölmesinde de duyulan 'kader teması' birkaç kez arka arkaya duyulur ve koda-1 yarım kadansla sona erer.

239. ölçüde yeni bir 'koda-2' başlar. Burada yine yan tema, 1. grubun temas1 kullanılmıştır. Tema parçalanarak devam eder ve 250. ölçüde tam otantik kadansla sona erer. Ardından kadansın uzaması başar. 258. ölçüde yan tema, 1. grubun temasının ilk motifinin duyulup, uzamasıyla 'Allegro assai' başl1klı birinci bölüm sona erer.

\section{2. İkinci Bölüm 'Andante con moto'}

Sonatın ikinci bölümü olan 'Andante con moto', 'çeşitleme' formundadır; tema ve dört çeşitlemeden oluşur. İlk bölümün karamsar başlangıcıyla tezatlık oluşturan, Şekil 5'te görülen, re bemol majör tema, 1.-16. ölçüler arasında duyulur. Tema, kendi içinde iki kısımdan oluşur; ilk sekiz ölçü ilk, 9.-16. ölçüler ise ikinci kısımdır. Her iki temada da noktalı-on altılık ritim kalıbı kullanılmıştır. Koral'i andıran ikinci bölüm, ilk bölümde ana temanın geniş aralıklı arpejlerinden farklı olarak oldukça durağandır.

Şekil 5. Tema (1.-16. ölçüler)

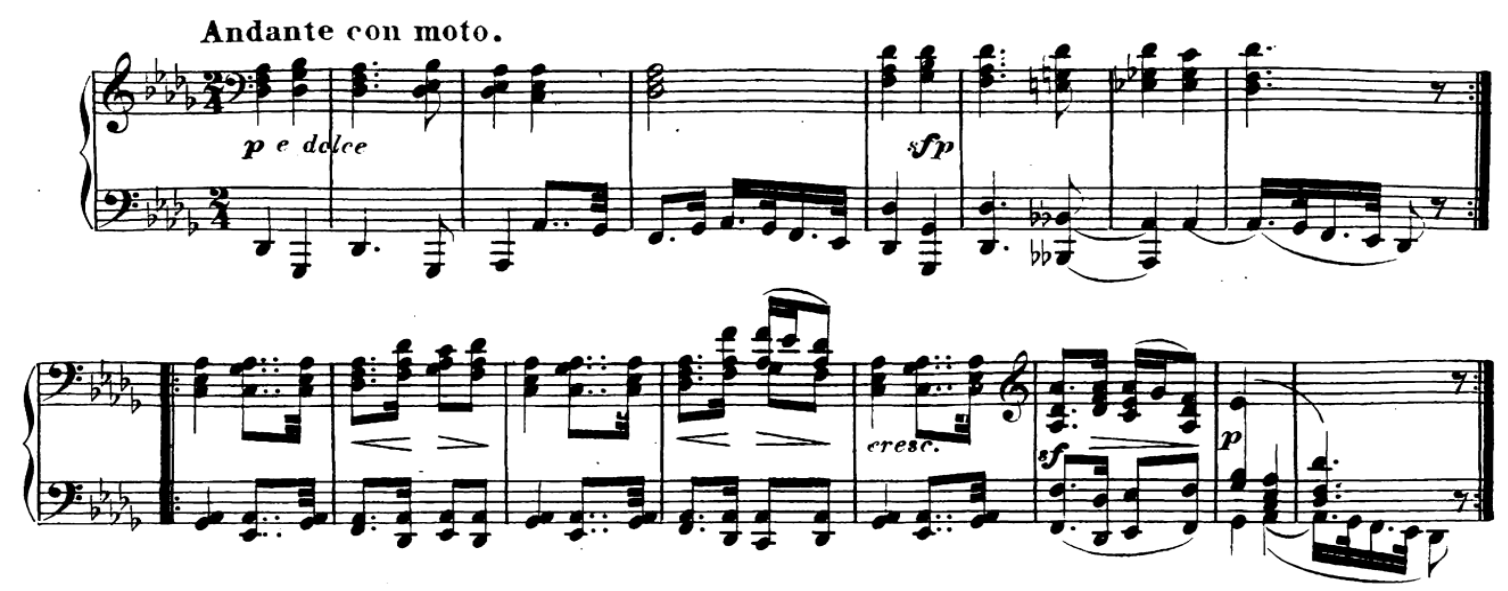

1. Çeşitleme, 17.-32. ölçüler arasındadır. Bu çeşitlemede, sağ elde tema devam ederken, sol ele senkoplar eklenmiştir. Bu çeşitleme de tema gibi sekiz ölçülük iki kısımdan oluşur.

2. Çeşitleme, 33. ölçüde başlar ve 48. ölçünün ikinci yarısına kadar devam eder. Bu kez tema sol elde duyulurken, sağ el arpejlerle eşlik eder. 2. çeşitleme, tema ve 1. çeşitlemenin aksine nota üzerinde legato olarak belirtilmiştir.

3. Çeşitleme, 49.-80. ölçüler arasındadır. Bu çeşitlemenin dikkat çekici özelliği, 1. ve 2. çeşitlemelerin her ikisini de içinde barındırmasıdır. 2. çeşitlemedeki on altılık arpejler, otuz ikilik notalara dönüşmüş, tema ise sağ elde senkoplarla ve $s f$ ile belirgin bir şekilde duyulur. 57. ölçüde tema sol ele, ardından 65. ölçüde tekrar sağ ele geçer. 79. ölçüde $f f$ sadece tek ölçülük bir diminuendo ile $p$ 'ye düşen 4. çeşitlemeye bağlanır ve tema röpriz olmadan tekrar 
duyulur. Bu çeşitlemede tema, oktav atlamalarıyla devam eder. 4. çeşitleme, form olarak röpriz ve koda yerine geçer. Eksik yedili akorla bölüm sona erer. İkinci gelen eksik akor ff ve üçüncü bölümün habercisidir.

\section{3. Üçüncü Bölüm 'Allegro, ma non troppo'}

Sonatın üçüncü ve son bölümü olan 'Allegro, ma non troppo', birinci bölüm gibi 'sonat allegro' formunda bestelenmiştir; bölüm boyunca gergin bir atmosfer hissedilmektedir. Fa minör bölüm on dokuz ölçülük bir girişle, ikinci bölümün sonundaki eksik akorun ssrarlı tekrarlarıyla başlar. Burada ilk iki ölçüdeki ritim, sonraki iki ölçüde iki kat hızlanarak Beethoven'ın bir çağrısı ve ikazı olarak nitelendirilebilir. Müzikte eksik yedili akorlar genellikle gerginlik hissini vermek için kullanılır. Akorların ardından gelen on altılık pasaj sergi bölmesine hazırlık niteliğindedir.

20.-117. ölçüler arasında duyulan 'sergi' bölmesinin enerjik ve heyecanlı bir karakteri vardır. Ana tema, iki gruptan oluşur; ilki Şekil 6'da görülen 20.-28. ölçüler arası, ikincisi de Şekil 7'de görülen 36.-50. ölçüler arasında duyulur. Her ikisi de 'bileşik aperyodik' temadır. Ana temanın 1. grubu 20. ölçüde başlar ve ardından gelen sekiz ölçüde bu kez akor ve oktavlardan oluşan eşlikle temayı tekrar eder. 28. ölçüde 'geçit' başlar, 36. ölçüde yine fa minör ana tema grubunun 2. grubu duyulur ve 50. ölçüye kadar devam eder. 50.-64. ölçüler arası ana temanın 2. grubu bu sefer sağ ele geçerek tekrar eder. 64. ölçüde, bölümün en başında duyulan motifle geçit başlar ve 75. ölçüye kadar devam eder. 76. ölçüde Şekil 8'de görülen do minör yan tema duyulur. Yan tema, ilk dört ölçüsü uzaması ve ardından tekrarıyla 96. ölçüye kadar devam eder ve 96. ölçüde 'kodetta' başlar. Kodetta, ilk temadan alınan motifle işlenmiş ve tekrarlanmıştır.

Şekil 6. Ana tema, 1. grup. (20-28. ölçüler)
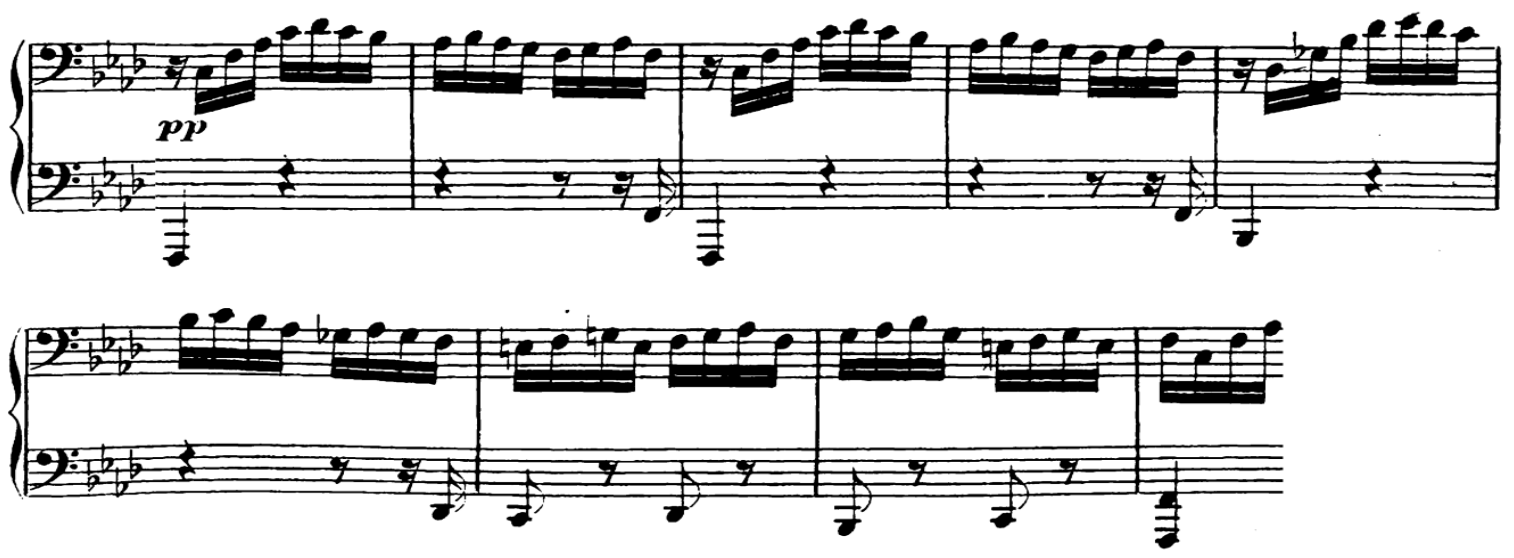

Şekil 7. Ana tema ikinci grup (36.-50. ölçüler)
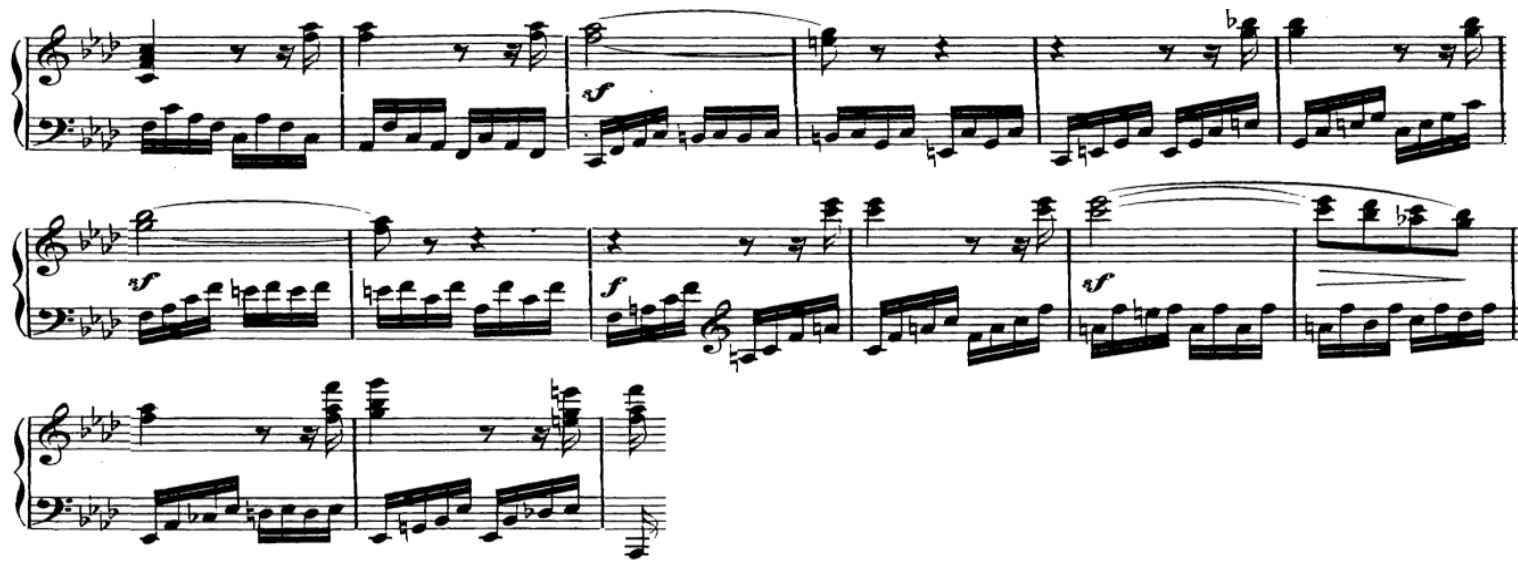

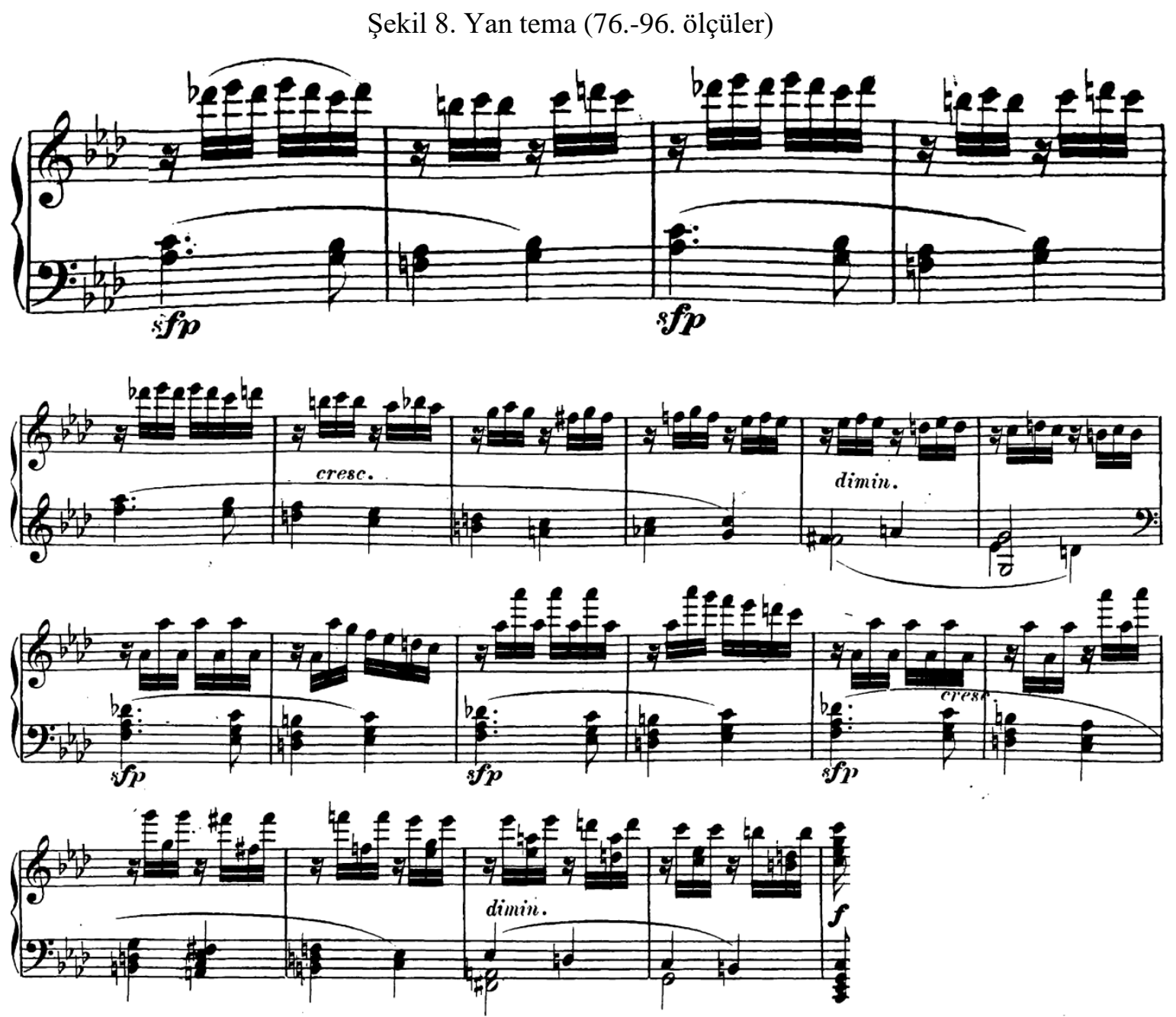

118.-211. ölçüler bölümün 'gelişme bölmesi'dir. Gelişme bölmesi 'ön hazırlık', 'ana grup' ve 'yeniden geçit' olmak üzere üç grupta incelenmiştir. 118.-126. ölçüler tonal kararlılığın bozulduğu, ana grubun ön hazırlı̆̆ıdır. 126. ölçüde başlayan sergi bölmesinin ilk teması 142. ölçüye kadar devam eder; burada duyulan senkoplarla ikinci bölümün 3. çeşitlemesi arasında yapısal bir bağ saptamak mümkündür. 158. ölçüde tekrar sergi bölmesinden ilk temanın iki ölçülük motifiyle 'geçit' başlar, 175. ölçüye kadar devam eder ve 176. ölçüde 'geri geçit' başlar. Burada tema genişletilerek kullanılmıştır. Yeniden sergi bölmesine hazırlık olan 'geri geçit', arpejlerden oluşur ve ana ton olan fa minöre hazırlık niteliğindedir. 206. ölçüde fa minörün dominantı duyulur ardından 212. ölçüde 'yeniden sergi' başlar.

Yeniden sergi bölmesinde 1. tema, sergi bölmesinde ilk başladığı haliyle değil, 28. ölçüdeki haliyle duyulur, ardından 220. ölçüde sol elde tema devam ederken, sağ elde yeni bir motif ortaya çıkar ve 228. ölçüde fa minör ana tema grubunun 2. teması başlar. Tema, 256. ölçüye kadar devam eder ve sergi bölmesinde olduğu gibi ilk temadan alınan motifle256. ölçüde 'geçit' başlar. Geçit, sergi bölmesinden farklı olarak bu sefer fa minör başlayıp, re bemol majöre geçer. 268.-288. ölçülerde sergi bölmesinde olduğu gibi yan tema duyulur. Yan tema burada fa minördür.

288. ölçüde 1. temadan alınan motifle fa minör tonalitesinde 'koda-1' başlar. Koda-1, 300. ölçüye kadar sergi bölmesindeki haliyle duyulur, 300. ölçüde geçitten alınan motif, 308. ölçüye kadar devam eder ve 308. ölçüde 'koda-2' başlar. 
Koda-2, yeni bir temayla başlar; akorlardan oluşan bu güçlü tema önce ana ton olan fa minör, ardından da la bemol majörde tekrar eder. 325. ölçüde ana temadan alınan motif duyulur; burada geri geçitte duyulan motif sol ele geçer ve 341. ölçüye kadar devam eder. Tam otantik kadansın duyulmasının ardından kadansın uzaması başlar. Tekrar eden arpejler ve akorlarla 'Allegro, ma non troppo' güçlü bir şekilde sona erer.

\section{Appassionata Sonatı'nın Yorumculuk Bakımından İncelenmesi}

'Appassionata Sonatı'nın birinci bölümü, birkaç yorumcudan dinlenmiş ve aşağıda Wilhelm Kempff, Alfred Brendel ve Vladimir Horowitz'in yorumlarıyla ilgili görüşlere yer verilmiştir.

\subsection{Birinci Bölüm 'Allegro Assai'}

'Allegro assai' başlıklı birinci bölüm, yavaş bir tempoda olmasa da karamsar karakterine uygun yorumlanması ve özellikle girişin ritmik keskinliğinin duyulması açısından oldukça önemlidir. Ayrıca ilk cümleyi aksansız, belirgin bir legato ile çalmak eserin başlangıcı için dikkat çekici olacaktır.

Kempff'in 1960 yılında yaptığı kayıtta, gereğinden ne hızlı ne de yavaş, orta karar bir tempo tercih edilmiştir. Girişte az pedal kullanılmış ve trillerin tümüne alttan başlanmıştır. 14. ölçüde 'a tempo' başladığında oldukça dinamik bir tempo alınmıştır. 24. ve 25. ölçülerde suslar yapılmamış, sesler pedalda uzamıştır. 28. ölçüde pasaj, pedalsız ve suslar dikkate alınarak çalınsa da 29. ölçüde gelen aynı motif, suslar yapılmadan, pedallı çalınmıştır. 35. ölçüde yan temanın 1. grubu geldiğinde daha sakin bir tempoya geçilmiş; ancak nota üzerinde böyle bir ifade bulunmamaktadır. 51. ölçüde gelen tema ve öncesinde gelen geçidin sonu birbirine bağlanmıştır. Beethoven'ın buradaki yazısında bağ kesilse de Kempff' in kaydında, crescendo yapılarak geçit ve tema bağlı çalınmıştır. 51. ölçüde başlayan yan tema 2. grup, pedallı ve artiküle edilmeden bağlı çalınmıştır; fakat yine de sağ elde üst sesler duyulmaktadır. 70. ve 72 . ölçülerde neredeyse tam bir ölçü boyunca devam eden suslar pedalın içinde kalmıştır. 92. ölçüden sonra gelen temada her üç kayıt da stil olarak benzemektedir; fakat Kempff' in kaydında 97. ve 98. ölçülerde oktav çıkan sesler daha kısa ve pedalsız çalınmıştır. 108. ölçüden sonra nüans farklılıkları çok belirgin ve tempo korunmuştur. 123. ölçüde gelen sekizlik notalar pasaja dahil edilmeden, Beethoven'ın belirttiği şekilde uzun çalınmış, pedallı olsa da tüm sesler artiküle bir şekilde duyulmuştur. 135. ölçüde notada belirtilmese de temaya ritardando yaparak başlanmıştır. 144. ölçüden sonra tekrar tekrar duyulan 'kader teması' keskin ve artiküle çalınmıştır. 204. ölçüde kodada sağ el, artiküle başlamış, sonra pedallı devam etmiştir. 208. ölçüyle birlikte nota üzerinde yazıldığı gibi dört ölçü boyunca crescendo yapılmış; fakat 210 . ölçüye nota üzerinde belirtildiği gibi $p$ başlanmamıştır. 235. ölçüde 'si bemol' $p$ değil $f$ çalınmış, sonrasında tekrar eden 'kader teması'nda nota üzerinde belirtilen sempre ped. dikkate alınmamıştır. 'Adagio' öncesindeki ritardando Brendel'in kaydına göre daha geç uygulanmaya başlanmıştır. 'Piu Allegro'ya dinamik bir tempoyla başlanmış ve son dört ölçüye kadar tempo korunmuştur; fakat bölümün sonunda aşırı bir yavaşlama yapılmış ki nota üzerinde böyle bir ibare yoktur.

Brendel'in, 1971 yılında yaptığı kayıtta sonatın birinci bölümüne oldukça serbest başlanmış, 'a tempo' öncesi Kempff ve Horowitz'in kayıtlarına göre (nota üzerinde poco rit. olarak belirtilmesine rağmen) fazla yavaşlama yapılmıştır. 14. ölçüde 'a tempo'da notalar, rafine ve çok parlak duyulmuş, sonrasında nota üzerinde belirtilen nüans farklılıkları ( $f f$ ve $p$ ) pek anlaşılmamaktadır. 28. ve 29. ölçülerde suslar dikkate alınmamış, pedalın içinde kalmıştır. 33. ve 34. ölçülerde suslar pedal içinde kalmış ve nota üzerinde belirtilmemesine rağmen ritardando yapılmıştır. Brendel'in kaydında da Kempff' in kaydında olduğu gibi 35. ölçüde yan tema 1. grup geldiğinde daha sakin bir tempoya geçilmiştir. 47. ölçüde başlayan kromatik gam, 51. ölçüde $f$ nüansındaki tema öncesi aksansız, sade ve $p$ çalınmış, böylece 51. ölçüde gelen tema daha etkili duyulmuştur. Tema başlamadan önce ufak bir duraksama yapılmıştır; bunun sebebi bestecinin yazdığı bağın bitmesi ve yeni bir bölmeye geçilmesi olabilir. Temada sağ elde 
üst sesler alt seslerden ayrılmış ve on altılık notalar Kempff' in kaydına göre daha artiküle çalınmıştır. 93.-104. ölçüler arası suslar pedal içinde kalmıştır. 108. ölçüden sonra nüanslar Kempff'in kaydındaki kadar belirgin olmamıştır. 126. ölçüde üst sesler ön plana çıkarılmış ve ardından 134. ölçüde non-legato başlayan do notalarına decrescendo ile birlikte pedallı devam edilmiş, yeniden sergi bölmesine bu şekilde bir hazırlık yapılmıştır. 149. ölçüde başlayan arpejde nota üzerinde belirtildiği gibi crescendo yapılmamış, 150. ölçünün sonunda yavaşlanmıştır. Brendel'in kaydında da Kempff'in kaydında olduğu gibi 204. ölçüde kodaya pedalsız ve artiküle başlanıp, ardından pedalla devam edildiği gözlemlenmiş̧ir. 218. ölçüden sonra gelen arpejler pedallı çalınmış, tüm notalar parlak bir şekilde ortaya çıkarılmıştır. 235. ölçüde ve sonrasında duyulan 'kader teması' notanın üzerinde belirtildiği gibi iki buçuk ölçü boyunca tek pedalda çalınmıştır. 'Piu Allegro' öncesi nota üzerinde belirtildiğinin aksine büyük bir yavaşlama yapılarak 'Adagio'ya ulaşılmıştır. 'Piu Allegro'ya dinamik bir tempoyla başlanmış ve son iki ölçüye kadar bu tempo korunmuştur. Brendel'in kaydında da Kempff'in kaydında olduğu gibi nota üzerinde belirtilmemesine rağmen son iki ölçüde yavaşlama yapılarak bölüm bitirilmiştir.

Horowitz'in 1959 yılında yaptığı kayıtta, Kempff ve Brendel'in kayıtlarına göre en dikkat çeken farklılık girişte trillerin sonundaki yavaşlama olmuş, trillerden sonra gelen notalar değerlerinden uzun çalınmıştır. Bu da daha sonatın girişinde Horowitz'in kaydının, Kempff ve Brendel'in kayıtlarına göre daha serbest olacağının sinyallerini vermektedir. Bağlı notaların ardından gelen on altılıklarda aksanlar duyulmaktadır. 14. ölçüde 'a tempo'da çok hızlı bir tempo alınmamış, yine arkasından gelen temada da aynı oturaklı tempo korunmuştur. Kempff ve Brendel'in kayıtlarında olduğu gibi 28. ve 29. ölçülerde suslar pedal içinde kalmıştır. 35. ölçüde tema geldiğinde tempo korunmuştur. 39. ölçüde bağ ve cümle sonu olan 'mi bemol' aksanlı duyulmaktadır. 44, 45, ve 46. ölçülerde gelen trillerde, ilk notalarda duraksayarak çalınmıştır. 50. ölçünün sonundaki bağ belirtilmeden temaya geçilmiş, 51. ölçüde tema başladığında tempo düşürülmüştür. Tema, pedallı ve bağlı çalınırken sağ elde üst sesler net bir şekilde duyulsa da tema dışı sesler de yoğun bir şekilde duyulmaktadır. 70. ve 72. ölçülerde suslar yapılmamıştır. 94. ölçüden sonra tempo yavaşlamış, 97. ve 98. ölçülerde suslar pedal içinde kalmıştır. 108. ölçüden sonra nota üzerinde belirtilen $p$ ve $f$ nüans farkl11ıkları Kempff ve Brendel'in kayıtlarına göre daha belirgin duyulmaktadır. 123.-132. ölçüler nota üzerinde belirtildiği gibi sempre ped. çalınmıştır. 144. ölçüden sonra üç vuruş uzayan sesler ortaya çıkarılmış, 149. ölçüde gelen arpej çok artiküle olmamakla birlikte, sol elde tekrar eden do sesi ön plana çıkarılmıştır. Diğer kayıtlardan farklı olarak 204. ölçüden sonra Horowitz'in kaydında, sağ el artiküle çalınmayıp, sol eldeki tema ortaya çıkarılmıştır. 235. ölçü ve sonrasında duyulan 'kader teması' pedallı çalınsa da nota üzerinde belirtildiği gibi sempre değil kesik kesik duyulmaktadır. 'Piu Allegro' öncesi Horowitz'in kaydında yavaşlama olsa da Brendel'in kaydında olduğu gibi büyük bir yavaşlama yapılmamıştır. 'Piu Allegro'da Horowitz'in kaydında da Kempff ve Brendel'in kayıtlarındaki gibi oldukça dinamik bir tempo alınmış fakat diğer kayıtlardan farklı olarak sonunda hiç yavaşlamadan bölüm bitirilmiştir.

\section{2. İkinci ve Üçüncü Bölümler 'Andante con moto' 'Allegro, ma non troppo'}

'Andante con moto' başliklı ikinci bölümde, Urtex nota üzerinde legato belirtilmemiştir; fakat kayıtların üçünde de legato çalındığg görülmektedir.

Kempff'in kaydında, 'Andante con moto' başlıklı ikinci bölümde sakin ama akıcı bir tempoyla çalınmıştır. Genel olarak röprizler daha $p$ duyulmaktadır. 13. ölçüde noktalı ve otuz ikilik notadan oluşan ritim kalıbı, her iki sefer de noktalı ve on altılık olarak çalınmıştır. 33. ölçüde başlayan 2. çeşitlemede tema sol ele geçmiş olsa da her iki el de eşit duyulmuş, 3 . çeşitlemeyle birlikte bazen ritimle oynanmıştır. 79. ölçüde röpriz yapıp başa dönerken yavaşlayarak dönülmüş; fakat 4. çeşitlemeye geçerken hiç yavaşlamadan devam edilmiştir. Bölümün bitişine dört ölçü kala yavaşlamaya başlanmış, ilk akor yavaş ikincisi hızlı kırılmıştır. İkinci bölüm, hiç ara verilmeden (attacca) üçüncü bölüme bağlanmıştır. 
Kempff'in kaydında, 'Allegro, ma non troppo' başlıklı üçüncü bölüm, abartısız, orta hızda bir tempoyla çalınmıştır. 20. ölçüde başlayan sergi bölmesine pedalsız başlanmış, 36 . ölçüye kadar pedalsız devam edilmiş̧ir. 64. ölçüde başlayan geçitte tempo çekilmiş, sağ elde tema ortaya çıkarılsa da artiküle duyulmamıştır. Bölüm boyunca yoğun pedal kullanımı görülmemektedir. 112.-115. ölçüler arası vuruş başları aksanlı duyulmuş, gelişme bölmesi başlamadan önce yavaşlanmış ve 118. ölçüde tempoda devam edilmiştir. 135. ölçü ve sonrasında üst notalar oldukça belirgin ve parlak duyulmuştur. 143. ölçüden sonra sağ elde gelen tema, tek ses olduğunda nota üzerinde belirtildiği gibi staccato, fakat oktav çalındığında pedallı ve uzun çalınmıştır. 168.-175. ölçüler arası sol el ön plana çıkarılmış ve 176. ölçüye kadar nota üzerinde belirtilmese de hızlanarak devam edilmiştir. 184,186,188,190. ölçüler nota üzerinde belirtildiği gibi pedallı çalınmamış; fakat sonrasında 192. ölçüden 204. ölçüye kadar notada belirtildiği gibi sempre ped. çalınmıştır. 211. ölçüdeki noktalı ritim kalıbı non-legato duyulmaktadır. Yeniden sergiye nota üzerinde belirtildiği gibi $p p$ başlanmamıştır. 300. ölçüden sonra hızlanarak, hiç ara verilmeden koda-2'ye bağlanmıştır. Koda-2'ye çok hızlı olmayan, oturaklı bir tempoyla başlanmış, sonradan hızlanılmış, arkasından pedalsız, kısa ve keskin akorlarla bölüm sona ermiştir.

Brendel'in kaydında Kempff' in kaydına göre 'Andante con moto' başlıklı ikinci bölüm, daha yavaş bir tempoyla çalınmıştır. 1. çeşitlemede nota aralarındaki sekizlik ve on altılık suslar pedal içinde kalmıştır. 2. çeşitlemede Kempff'in kaydında olduğu gibi her iki el de eşit duyulmuştur. 3. çeşitleme, Kempff' in kaydı göre daha ritmik çalınmış ve otuz ikilik notalar oldukça parlak duyulmuştur. 3. çeşitleme ve sonrasında bir el otuz ikiliklerle eşlik ederken, diğer elde çalan tema, her seferinde ortaya çıkarılmıştır. 79. ölçüden 4. çeşitlemeye hafif yavaşlayarak geçilmiştir. Bölüm sonundaki $p$ akor çok yavaş kırılmış, $f$ akor ise ilkinin aksine hızlı kırılmıştır.

Brendel'in kaydında, 'Allegro, ma non troppo' başlıklı üçüncü bölümde, Kempff' in kaydına göre biraz daha hızlı bir tempo alınmıştır. Ayrıca stil olarak iki kayıt arasında büyük benzerlik görülmektedir. 20. ölçüde başlayan sergi bölmesine pedalsız başlanmış, 36. ölçüye kadar pedalsız devam edilmiştir. Üçüncü bölümde, Brendel'in kaydında, Kempff'in kaydına göre daha yoğun pedal kullanımı görülmektedir. 64. ölçüde başlayan geçitte nota üzerinde belirtilen crescendo ve decrescendo oldukça belirgin bir şekilde duyulmaktadır. 104. ölçü ve sonrasında nota üzerindeki $s f$, yazan akorlarda değil, ölçü başlarındaki akorlarda yapılmıştır. 125. ölçüde tempo esnetilmiş ve 126. ölçüde temaya kısa bir boşluğun ardından başlanmıştır. Brendel'in kaydında da Kempff'in kaydında olduğu gibi tema tek ses olarak geldiğinde nota üzerinde belirtildiği gibi staccato, fakat oktav çalındığı yerlerde pedallı çalınmıştır. 168. ölçüden sonra sol eldeki notalar ön plana çıkarılmıştır. 206. ölçüden yeniden sergi başlayana kadar tempo esnetilmiş, 211. ölçünün ikinci vuruşunda noktalı ve on alt1liktan oluşan ritm, non-legato ve tempoda çalınarak yeniden serginin ilk temasına başlanmıştır. 300. ölçüden sonra hızlanarak koda-2'ye bağlanmıştır; Kempff' in kaydına göre burada daha hızlı bir tempoyla çalındığ görülmektedir. 'Presto' öncesi crescendo yapılmış fakat nota üzerinde yazıldığı gibi ff başlanmamış ve yine arkasından $p$ yapılmamıştır. 325. ölçüden önce yavaşlama yapılmış, sonrasında da tempo hızlandırılmıştır. Koda-2 parlak ve artiküle duyulmaktadır. Bitişten on ölçü önce yavaşlama yapılmış, arkasından gelen arpejler son akorlara kadar tek pedalda ve oldukça enerjik duyulmaktadır. Sondaki akorlar tek pedal içinde olmasa da Kempff' in kaydına göre daha pedallı ve uzun duyulmaktadır. (Son dokuz ölçü nota üzerinde tek pedal olarak belirtilmiştir.)

Horowitz'in kaydında 'Andante con moto' başlıklı ikinci bölümde, Kempff ve Brendel'in kayıtlarına göre daha geniş bir nüans aralığında ve daha hızlı bir tempo ile çalındığ 1 görülmektedir. 1. çeşitlemede nota üzerinde belirtilmese de tempo arttırılmış, suslar pedal içinde kalmıştır. 33. ölçüde başlayan 2. çeşitlemede tema ve eşlik eşit çalınmıştır. 3. çeşitlemeye yavaş başlanıp, sonradan hızlanılmış ve pedallı çalınmıştır. 4. çeşitlemeye yavaşlamadan geçilmiş, 
bölümün sonunda Kempff ve Brendel gibi Horowitz'in kaydında da ilk akor yavaş, ikinci akor hızlı kırılmıştır. İkinci bölüm hiç ara verilmeden üçüncü bölüme bağlanmıştır.

'Allegro, ma non troppo' başlıklı üçüncü bölüme, orta hızda bir tempoyla başlanmış; fakat bölüm boyunca tempo sürekli değişmiştir. 28'den 29. ölçüye geçerken rubato yapılmış ki bu yorumla dönemin stil özellikleri ve bu ölçüdeki karakter göz önüne alındığında çerçeveden uzak, fazla serbest bir rubato yapıldığı saptanabilir. 50. ölçüde hızlanılmış, 64. ölçüde başlayan geçitte yine oldukça dalgalı bir tempo alınmış ve arkasından tekrar hızlanılmıştır. 118. ölçüde gelişme bölmesine başlamadan önce, Kempff'in kaydının aksine Horowitz'in kaydında yavaşlama yapılmamış, aynı tempoda devam edilmiştir. Gelişme bölmesinde nota üzerinde belirtilen nüanslar Kempff ve Brendel'in kayıtlarına göre daha açık duyulmaktadır. 135. ölçüde eser içinde tek bir kere duyulan üst sesler ön plana çıkarılmış, 138. ölçüyle birlikte tempo tekrar hızlandırılmıştır. 168. ölçüden sonra Kempff ve Brendel'in kayıtlarında olduğu gibi sol eldeki sesler ön plana çıkarılmıştır. 179. ve 183. ölçülerde nota üzerinde belirtilen ve bir ölçü boyunca devam eden suslar pedal içinde kalmıştır. 192.-204. ölçüler nota üzerinde belirtildiği gibi sempre ped. çalınmış, 198. ölçüde notada belirtilmemiş olsa da crescendo yapılmıştır. Yeniden sergi bölmesinde tempo yine değişmektedir. 300. ölçüden itibaren hızlanarak koda-2'ye ulaşılmış, her iki kayda göre çok daha hızlı bir tempo tercih edilmiştir. 352. ölçüde Kempff ve Brendel'in kayıtlarındaki gibi yavaşlanmamış; arpej, nota üzerinde belirtildiği gibi tek bir pedalda çalınmıştır. Sondaki akorlar ise Brendel'in kaydında olduğu gibi uzun ve pedallı duyulmaktadir.

\section{Yöntem}

$\mathrm{Bu}$ araştırma, Ludwig van Beethoven'ın sanatını, eserlerini, değişen üslubunu, 'Appassionata Sonatı'nı araştıran ve tarama modeline dayanan betimsel bir çalışmadır. Ayrıca yaşamında, eserlerini etkileyen önemli unsurlara da yer verilmesi sebebiyle biyografik bir araştırmayı da içermektedir.

Betimleme yöntemi, tüm bilim kollarında ilk aşamayı oluşturur; amacı araştırma konusu olguları ve bu olgular arasındaki ilişkileri saptama, sınıflandırma ve kaydetmedir. Betimsel araştırmalar, olayların, objelerin, varlıkların, kurumların, grupların ve çeşitli alanların "ne" olduğunu betimlemeye, açıklamaya çalışır. Bu tür incelemeler mevcut durumları, şartları ve özellikleri olduğu gibi ortaya koymayı amaçlar. Buna 'tarama modeli' de denilmektedir. Verilerin analizi ve açıklanması suretiyle yorumlama, değerlendirme ve yeni durumlara uygulanacak şekilde genellemelere varma gibi işlemlere yer vermektedir. (Şen, 2005, s. 346)

\section{Bulgular}

Kempff, Brendel ve Horowitz'in kayıtlarına bakıldığında stil olarak birbirinden farklı üç kayıt görülmektedir. Kempff ve Brendel'in kayıtları stil olarak birbirine benzerken Horowitz'in onlardan çok daha serbest bir stilde yorumladığı düşünülmektedir. Kempff ve Brendel'in yorumlarında Horowitz'in kaydına göre daha az pedal kullanıldığ daha sabit bir tempoda çalındığı görülmüştür. Ayrıca Kempff ve Brendel'in kayıtlarında nüansların dengeli olduğu gözlemlenmiş, temaların karakter farklılıkları anlaşı1ır bir şekilde yorumlanmıştır. Yeni gelen tema ve bölmelerden önce hazırlık yapılmış, forma önem vererek yorumlanmıştır. Kempff ve Brendel'in kayıtlarında bölüm içinde tempo değişiklikleri olsa da aşırıya kaçılmamıştır. Horowitz'in kaydında ise üç bölümde de temponun, nota üzerinde belirtilmediğinde de zaman zaman değiştiği görülmüş, nota üzerinde belirtilen susların da bazı yerlerde pedal içinde kaldığı ya da yapılmadığ gözlemlenmiştir.

\section{Tartışma}

'Appassionata Sonat'1, Beethoven'ın klasik stilden uzaklaşmaya başladığ bir döneme denk geldiği için elbette ki yorumlardan birine yanlış birine doğru demek doğru değildir fakat bir tercih yapılacak olursa Kempff ve Brendel'in kaydının dönemi daha iyi yansıttı̆̆ı, Horowitz'in kaydının ise besteciden çok yoruma odaklı olduğu düşünülmektedir. 


\section{Sonuç ve Öneriler}

Beethoven, yaşamının her üç döneminde de form, stil ve yorumculuk açısından incelendiğinde öğretici ve gelecek nesillere yol gösterecek eserler ortaya çıkarmıştır. Bu çalışmada, bestecinin genel olarak yaşamı, üç ayrı dönemde incelenen eserleri ve stili, orta döneminde bestelediği 'Appassionata Sonatı'nın form analizi ve yorumculuk bakımından üç ayrı piyanistin yorumu ele alınmıştır.

'Appassionata Sonat'1, Beethoven'ın sağlı̆̆ının git gide kötüleştiği bir dönemde bestelenmiş olup, bestecinin tüm sıkıntısını, karamsarlığını yansıtan bir eserdir. Sonat, klasik döneme ait bir eser olsa da romantik dönemde bestelenecek eserlerin bazı özelliklerinin sinyallerini vermiştir. 'Appassionata Sonatı'nı bestecinin diğer sonatlarından ayıran bazı özellikler vardır. Bu özelliklerden bazıları, bileşik aperiyodik tema kuruluşu kullanılması; ayrıca serim bölmesindeki yan temanın ilk grubunun 1. temadan çeşitlenmiş olması dönemin eserlerine bakıldığında oldukça dikkat çekicidir. Yine o dönemde sık rastlanmayan sergi bölmesinde gelen kadans cümlesinin ardından geçit getirilmeyip, temel fikir tekrar sunulmuştur. Birinci bölümde, oldukça geniş olan gelişme bölmesinde temalar parçalanarak kullanılmıştır. Ayrıca Beethoven sonraki yıllarda besteleyeceği ünlü 5. Senfonisi’nin motifini (kader temasını) sonatın birinci bölümü içinde kullanmıştır.

Çalışmada, Beethoven'ın klasik formdan uzaklaşmaya başladığı dönemde bestelediği bu eser, tüm özellikleri ve farklılıkları ile birlikte incelenerek, yorumculuk açısından da ayrı açılardan değerlendirilmiştir. Böylece eserin daha iyi anlaşılması ve çalışmadan faydalanacak akademisyen ve müzisyenlere, form analiziyle birlikte yorumculuk tercihlerine ilişkin bir fikir sunulması hedeflenmiştir. Her ne kadar dönem olarak birçok açıdan değişimin yaşandığı bir dönem olsa da notaya, dolayısıyla bestecinin isteklerine bağlı kalarak ve klasik dönem stiline uygun bir düşünceyle eserin ele alınması sağlıklı, besteci odaklı bir yorumun temelini oluşturacaktır.

\section{Kaynakça}

Altay, G. (2011). Periyodik, Aperyodik ve Karma Tema Kuruluşları, Form Bilgisi Ders Notları. Bilkent Üniversitesi, Ankara.

Altay, G. (2014). Ludwig van Beethoven. http://muziktarihindegezintiler.blogspot.com.tr/2014/09/ludwig-van-beethoven.html (Erişim Tarihi: 13.05.2018)

Bloomberg C. (2007). Beethoven's Piano Sonatas An Analyses of Compositional Trends from 1795-1822 (Yayımlanmamış Yüksek Lisans Tezi). Washington State University School of Music College of Liberal Arts, Washington.

Boran, İ. ve Yıldız Şenürkmez, K. (2010). Kültürel Tarih Işı̆̆ında Çoksesli Batı Müziği. İstanbul: Yapı Kredi Yayınları.

Caplin, W. E. (2000). Classical Form. Oxford: Oxford University Press.

Çakıcı Uzar, A. (2017). Beethoven'ın Son Dönem Üslubu, Son Piyano Sonatları,ve "Op.106, Hammerklavier”. Uludă̆ Üniversitesi Fen-Edebiyat Fakültesi Sosyal Bilimler Dergisi, 18 (33): 379-399.

İlyasoğlu, E. (1994). Zaman İçinde Müzik. İstanbul: Yapı Kredi Yayınları.

Karaçil, V. (2010). L.Van Beethoven'in Op.90 Mi Minör, Op.101 La Majör, Op.109 La Majör, Op.110 La Bemol Majör Piyano Sonatlarının İncelenmesi (Yayımlanmamış Yüksek Lisans Tezi). Dokuz Eylül Üniversitesi Güzel Sanatlar Enstitüsü Müzik Anasanat Dalı, İzmir.

Lockwood, L. (2013). Beethoven Müzik ve Hayat (The Music and the Life) (Kılıç, Çev.). İstanbul: Türkiye İş Bankası Yayınları. 
Ludwig van Beethoven (2009). Piano Sonata No.23, Op.57 "Appassionata" http://www.classicalnotes.net/classics3/appassionata.html (Erişim Tarihi:17.12.2017).

Mimaroğul, İ. (2009). Müzik Tarihi. İstanbul: Varlık Yayınları.

Şen, Ü. (2005). Sanat Eğitiminde Bilimsel Araştırma Yöntemlerinin Kullanılması, Atatürk Üniversitesi Sosyal Bilimler Enstitüsü Dergisi, 5(1):343-360.

Youtube. Kempff, W. (1960)Stüdyo Kaydı. https://www.youtube.com/watch?v=UCbLHfYkiwg (Erişim Tarihi: 10.10.2020)

Youtube. Brendel, A. (1971) Stüdyo Kaydı. https://www.youtube.com/watch?v=5knEJumGjNI (Erişim Tarihi: 10.10.2020)

Youtube. Horowitz, V.(1959)Stüdyo Kaydı.https://www.youtube.com/watch?v=nrYaWqdePXQ (Erişim Tarihi: 10.10.2020)

\section{ETİK ve BİLİMSEL İLKELER SORUMLULUK BEYANI}

Bu çalışmanın tüm hazırlanma süreçlerinde etik kurallara ve bilimsel atıf gösterme ilkelerine riayet edildiğini yazar(lar) beyan eder. Aksi bir durumun tespiti halinde Afyon Kocatepe Üniversitesi Sosyal Bilimler Dergisi'nin hiçbir sorumluluğu olmayıp, tüm sorumluluk makale yazarlarına aittir. 